\title{
Late Gadolinium Enhancement Cardiac Magnetic Resonance Imaging: From Basic Concepts to Emerging Methods
}

\section{Kardiale Magnetresonanztomografie mit Late-Gadolinium- Enhancement: Vom Grundprinzip zu neuen Methoden}

Authors

Robert J. Holtackers ${ }^{1,2,3}$, Tilman Emrich4, 5, 6, René M. Botnar ${ }^{3,7}$, M. Eline Kooi ${ }^{1,2}$, Joachim E. Wildberger ${ }^{1,2}$, K.-F. Kreitner ${ }^{4}$

Affiliations

1 Cardiovascular Research Institute Maastricht (CARIM), Maastricht University, the Netherlands

2 Department of Radiology \& Nuclear Medicine, Maastricht University Medical Centre, the Netherlands

3 School of Biomedical Engineering \& Imaging Sciences, King's College London, United Kingdom

4 Department of Diagnostic and Interventional Radiology, University Medical Center Mainz, Germany

5 German Center for Cardiovascular Research (DZHK), Partner Site Rhine Main, Mainz, Germany

6 Department of Radiology and Radiological Science, Medical University of South Carolina, Charleston, SC, USA

7 Pontificia Universidad Católica de Chile, Escuela de Ingeniería, Santiago, Chile

Key words cardiac, heart, tissue characterization, MR imaging

received 14.10.2021

accepted 21.11.2021

published online 23.02.2022

Bibliography

Fortschr Röntgenstr 2022; 194: 491-504

DOI 10.1055/a-1718-4355

ISSN 1438-9029

(C) 2022. Thieme. All rights reserved.

Georg Thieme Verlag KG, Rüdigerstraße 14,

70469 Stuttgart, Germany

Correspondence

Robert J. Holtackers

Radiology \& Nuclear Medicine, Maastricht University Medical Centre+, Prof. Debyelaan 25, PO Box 5800, 6202 AZ

Maastricht, Netherlands

Tel.: +31/43/3874912

rob.holtackers@mumc.nl

\section{ABSTRACT}

Background Late gadolinium enhancement (LGE) is a widely used cardiac magnetic resonance imaging (MRI) technique to diagnose a broad range of ischemic and non-ischemic cardiomyopathies. Since its development and validation against his- tology already more than two decades ago, the clinical utility of LGE and its span of applications have increased considerably. Methods In this review we will present the basic concepts of LGE imaging and its diagnostic and prognostic value, elaborate on recent developments and emerging methods, and finally discuss future prospects.

Results Continuous developments in 3 $\mathrm{D}$ imaging methods, motion correction techniques, water/fat-separated imaging, darkblood methods, and scar quantification improved the performance and further expanded the clinical utility of LGE imaging. Conclusion LGE imaging is the current noninvasive reference standard for the assessment of myocardial viability. Improvements in spatial resolution, scar-to-blood contrast, and water/ fat-separated imaging further strengthened its position.

\section{Key Points:}

- LGE MRI is the reference standard for the noninvasive assessment of myocardial viability

- LGE MRI is used to diagnose a broad range of non-ischemic cardiomyopathies in everyday clinical practice.

- Improvements in spatial resolution and scar-to-blood contrast further strengthened its position

- Continuous developments improve its performance and further expand its clinical utility

\section{Citation Format}

- Holtackers RJ, Emrich T, Botnar RM et al. Late Gadolinium Enhancement Cardiac Magnetic Resonance Imaging: From Basic Concepts to Emerging Methods. Fortschr Röntgenstr 2022; 194: 491-504

\section{ZUSAMMENFASSUNG}

Hintergrund Das Late-Gadolinium-Enhancement (LGE) ist eine weit verbreitete Methode in der kardialen Magnetresonanztomografie (MRT) um ein breites Spektrum an ischämischen und nicht-ischämischen Kardiomyopathien zu diagnostizieren. Die klinische Anwendung und Nutzen haben sich seit der Entwicklung und histologischen Validierung des LGE vor mehr als zwei Jahrzehnten erheblich gesteigert.

Methoden In dieser Übersichtsarbeit wird das Grundprinzip der LGE-Bildgebung und der diagnostische und prognostische Wert vorgestellt, aktuelle Entwicklungen und neue Methoden erläutert und Zukunftsperspektiven diskutiert. 
Ergebnisse Kontinuierliche Weiterentwicklungen bei 3D-Bildgebungsmethoden, Bewegungskorrekturtechniken, wasser-/ fettgetrennter Bildgebung, Dark-Blood-Methoden und Narbenquantifizierung haben die Leistung und den klinischen Nutzen der LGE-Bildgebung weiter verbessert.

Schlussfolgerung Die LGE-Bildgebung ist der aktuelle nichtinvasive Referenzstandard für die Beurteilung der Myokardvitalität. Verbesserungen bei der räumlichen Auflösung, dem Narben-Blut-Kontrast und der wasser-/fettgetrennten Bildgebung haben diese Position weiter gestärkt.

\section{Kernaussagen:}

- LGE-MRT ist der Referenzstandard für die nichtinvasive Beurteilung der Myokardvitalität.

- Das LGE wird in der täglichen klinischen Praxis zur Diagnose eines breiten Spektrums nicht-ischämischer Kardiomyopathien eingesetzt.

- Verbesserungen der räumlichen Auflösung und des NarbenBlut-Kontrastes haben diese Position weiter gestärkt.

- Kontinuierliche Weiterentwicklungen verbessern die Leistung und erweitern den klinischen Nutzen.

\section{Introduction}

Late gadolinium enhancement (LGE), also known as delayed enhancement (DE) or late enhancement (LE), is a widely used cardiac magnetic resonance imaging (MRI) technique and the current noninvasive reference standard for the assessment of myocardial viability [1]. Since its initial validation against histology approximately two decades ago [2, 3], its ability to distinguish areas of myocardial infarction from normal myocardium has gained wide acceptance. Over the years, the clinical utility of LGE has broadened considerably, including the detection of non-ischemic enhancement patterns $[4,5]$, pre-procedural assessment of arrhythmogenic substrate $[6,7]$, and visualization of radiofrequency-induced ablation lesions [8, 9]. More recently, LGE emerged as a promising tool for guiding subsequent electrophysiology procedures to treat cardiac arrhythmias $[10,11]$. Nowadays, LGE is used to diagnose a broad range of ischemic and non-ischemic cardiomyopathies in everyday clinical practice.

In this review, we not only discuss the basic concepts of LGE imaging and its diagnostic and prognostic value, but also elaborate on emerging methods in the field of LGE, including darkblood techniques, high-resolution (isotropic) $3 \mathrm{D}$ imaging, water/ fat-separated methods, motion correction techniques, and semiautomated scar quantification.

\section{Basic LGE concepts}

LGE imaging requires the use of a gadolinium-based contrast agent (GBCA) which is intravenously administered to the patient. GBCAs are routinely used in MRI examinations for their strong $T_{1}$ shortening effect and tissue dependent distribution within the body. Particularly for LGE MRI, the time required for the GBCA to reach the cardiac tissue compartments after injection plays a major role in the acquired image contrast. As various compartments within the myocardium have different wash-in and washout kinetics, the GBCA concentration in these individual compartments will constantly vary after contrast injection [12]. While the GBCA reaches the normal myocardium already soon after injection, areas of fibrosis are reached at a much slower rate ( $\vee$ Fig. 1). A similar effect is observed for the clearance of the GBCA. While the GBCA is cleared quickly after reaching its peak concentration in the normal myocardium, it resides in areas of fibrosis for a much longer time.
Aside from the different wash-in and wash-out kinetics, the local distribution is of equal importance for LGE. The used GBCAs are extracellular and cannot cross the intact cell membranes of the normal myocardium, thereby limiting their distribution volume to the interstitial space. However, in patients with acute myocardial injury, the cell membranes of the affected myocytes have ruptured and the GBCA can now also access the 'intracellular' space, leading to an increased distribution volume [12]. Over time, scar tissue forms and the affected myocytes are replaced by a collagen matrix. As a result, the interstitial space is increased and thus also the distribution volume for GBCAs. Ultimately, both in patients with acute and chronic myocardial injury, the distribution volume for GBCAs is increased compared to that in healthy subjects. The combined effect of reduced wash-in/wash-out kinetics and the increased distribution volume leads to a delayed accumulation of the GBCA in areas of myocardial injury approximately ten minutes post-injection [13]. Because of the strong $T_{1}$ shortening effect of GBCAs, these areas of accumulation lead to a delayed hyperenhancement of the signal, hence the name "late enhancement" or "delayed enhancement".

\section{Standard LGE sequence}

While the areas of myocardial injury experience a strong decrease in $\mathrm{T}_{1}$ relaxation time due to prolonged GBCA accumulation, after approximately ten minutes most of the GBCA has already been cleared from the normal myocardium, resulting in a much longer $\mathrm{T}_{1}$ relaxation time there [13]. In order to maximize contrast between the normal myocardium and areas of myocardial injury, a heavily $T_{1}$-weighted segmented inversion-recovery (IR) gradient-echo pulse sequence is used ( $\bullet$ Fig. 2) [3]. IR pulse sequences start with a non-selective 180 -degree inversion radiofrequency (RF) pulse that inverts the longitudinal magnetization of all tissues. The IR pulse is followed by a time delay, called the "inversion time" or simply TI. During this delay, the longitudinal magnetization of all tissues will recover to its equilibrium with a rate determined by the tissue-specific $T_{1}$ relaxation time. Finally, after the TI, a spoiled gradient-echo readout of approximately 100$150 \mathrm{~ms}$ is performed to acquire the IR-prepared MR signal.

A “Look-Locker" scan, also known as a TI scout scan, provides a series of low-resolution images with an increasing $\mathrm{TI}$ and is usually performed prior to LGE imaging to determine the desired TI ( $\vee$ Fig. 3) [14]. Traditionally, the TI is set so that the longitudinal 


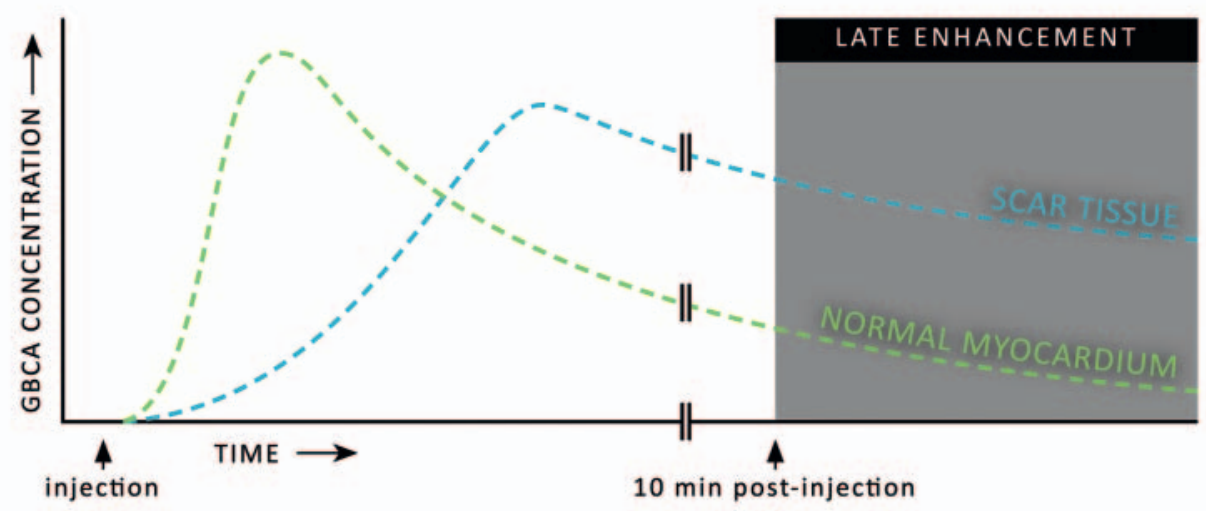

- Fig. 1 Schematic illustration of the gadolinium-based contrast agent (GBCA) concentration in both healthy myocardium (green) and scar tissue (cyan) after a bolus injection. While the GBCA quickly washes in and out of the normal myocardium, delayed wash-in and wash-out is observed for scar tissue. At approximately ten minutes post-injection, a phase known as "late (gadolinium) enhancement" commences (gray area), where scar tissue contains a significantly larger GBCA concentration compared to normal myocardium.

- Abb.1 Schematische Darstellung der Gadolinium-Kontrastmittel (GBCA)-Konzentration im gesunden Myokard (grün) als auch im Narbengewebe (cyan) nach einer Bolus-Injektion. Während das GBCA schnell in das normale Myokard ein- und ausgewaschen wird, wird im Narbengewebe ein verzögertes Ein- und Auswaschen beobachtet. Ungefähr zehn Minuten nach der Injektion beginnt eine als „Late (Gadolinium)-Enhancement“ bekannte Phase (grauer Bereich), in der Narbengewebe im Vergleich zu normalem Myokard eine signifikant höhere GBCA-Konzentration enthält.

magnetization of the normal myocardium is zero when the signal is acquired [15]. Nulling the normal myocardium will then lead to a black appearance on magnitude images, while the blood pool and areas of myocardial injury appear enhanced due to their shortened $\mathrm{T}_{1}$ relaxation time.

As an alternative to a conventional IR sequence, it is possible to use a phase-sensitive inversion-recovery (PSIR) sequence that applies a 180 degrees inversion RF pulse only once every two heartbeats ( $\vee$ Fig. 4 ). During every second heartbeat, a reference image is acquired using a low flip angle excitation (usually only 5 degrees). This reference image is used to determine the phase, and thus the sign, of the MR signals acquired every first heartbeat. PSIR is therefore able to distinguish positive from negative magnetization levels. Negative magnetization levels will be represented differently in the corrected real (or PSIR) image that is reconstructed: negative magnetization levels appear darkest, nulled magnetization levels appear mid-gray, and positive magnetization levels appear bright [16]. This is in contrast to conventional magnitude image reconstruction, where nulled magnetization levels appear darkest, and both negative and positive magnetization levels appear bright. When PSIR is used in combination with conventional myocardium-nulled LGE, the clinical observer may adjust window levels to further darken normal myocardial tissue, mimicking a magnitude image representation. In clinical practice, PSIR is recommended to make LGE image quality less sensitive to the chosen $\mathrm{TI}$, leading to a reduction in image artifacts and potential misinterpretations [1]. Additionally, in contrast to standard IR, PSIR is a so-called "two-beat" sequence with only a single inversion RF pulse every two heartbeats. Therefore, PSIR is more robust to heart rate variations and cardiac arrhythmias since it relies to a lesser extent on a constant time delay between successive inversion RF pulses, averaging irregular heartbeats over two heart beats. Inherently, however, scan duration doubles when using PSIR instead of standard IR.

\section{Free-breathing $3 \mathrm{D}$ methods}

Currently used clinical LGE techniques employ $2 \mathrm{D}$ breath-hold sequences, which are performed in 12-15 subsequent breath holds to cover the entire left ventricle (LV) in the short-axis view. Additional $2 \mathrm{D}$ breath-hold LGE scans can be acquired in the long-axis views for a complete LV evaluation. Such 2D LGE sequences generally provide very good image quality but may miss small infarcts due to the limited spatial resolution and associated partial volume effects. In addition, the repetitive breath holding can be challenging for elderly patients or patients with heart failure. Alternatively, free-breathing 3 D LGE imaging that is able to provide higher spatial resolution required for the visualization of small scar regions, and can be performed in patients who are unable to hold their breath, has been proposed. In addition, acquiring a whole-heart $3 \mathrm{D}$ volume with (near) isotropic resolution enables the use of multiplanar reformatting (MPR). Instead of being limited to prescribed short- and long-axis views, one can freely reconstruct any desired image orientation with sufficiently high spatial resolution ( $\vee$ Fig. 5).

Initial $3 \mathrm{D}$ implementations employed diaphragmatic navigators for respiratory motion correction and shorter acquisition windows to minimize cardiac motion but used the same magnetization preparation scheme and imaging sequence as the clinically used conventional 2 D LGE sequences $[17,18]$. As the IR preparation pulse is set to null normal myocardium, it also leads to a very low liver signal which can compromise the performance of the respiratory navigator. To overcome this challenge, the use of a navigator restore pulse that re-inverted the longitudinal signal in the liver immediately after the IR preparation pulse was proposed 


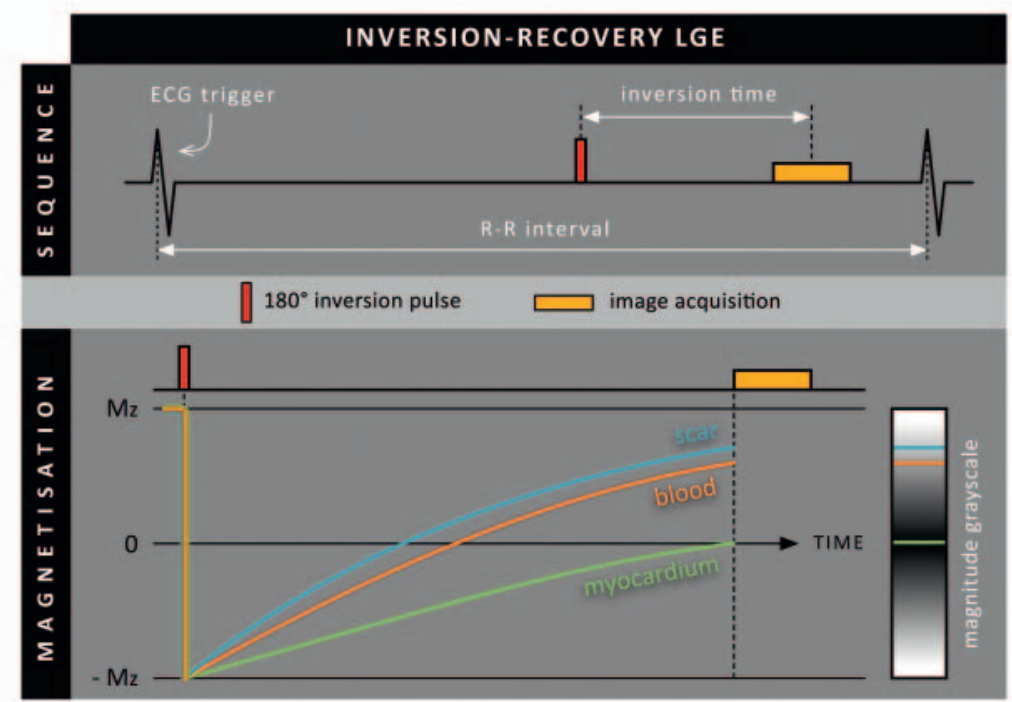

- Fig. 2 Conventional inversion-recovery sequence used for late gadolinium enhancement (LGE). A non-selective 180 degrees inversion radiofrequency pulse inverts all magnetization levels. A time delay follows, called the inversion time (TI), in which all longitudinal magnetization (Mz) levels recover with a rate determined by the tissue-dependent $\mathrm{T}_{1}$ relaxation time. Following the $\mathrm{TI}$, acquisition of the signal takes place. Note that for conventional LGE the $\mathrm{TI}$ is set to null the magnetization level of normal myocardium (green curve at 0 ), leading to a black appearance of the normal myocardium in the resulting (magnitude) image.

- Abb. 2 Konventionelle Inversion-Recovery-Sequenz für „Late Gadolinium-Enhancement“ (LGE). Ein nicht-selektiver 180-Grad Inversions-Radiofrequenzimpuls invertiert alle Magnetisierung. Es folgt eine Zeitverzögerung, die als Inversionszeit (TI) bezeichnet wird, in der sich alle Längsmagnetisierungen (Mz) abhängig von der gewebeabhängigen $\mathrm{T}_{1}$-Relaxationszeit erholen. Nach der Tl erfolgt die Akquisition des Signals. Für das konventionelle LGE wird die TI so eingestellt, dass die Magnetisierung des normalen Myokards (grüne Kurve bei 0 ) genullt ist, was zu einem schwarzen Erscheinungsbild des normalen Myokards im resultierenden (Magnituden-) Bild führt.

[18]. While this approach was successful in improving the performance of the navigator, the restore pulse also labelled blood in the vena cava that could lead to a high blood signal in the right heart chambers, which was especially challenging for LGE imaging of the right atrium. To address the blood labelling effect, a time delay between the navigator and the imaging sequence has been proposed. However, this solution prohibits motion correction due to the prolonged delay between navigator and imaging sequence [19]. Another approach employed an adaptive flip angle for the navigator restore pulse and effectively reduced the blood labelling artifacts [20]. Another challenge of 3 D LGE are frequent arrythmias which can disturb the steady state signal and consequently lead to severe ghosting artifacts. One solution is the use of an adaptive flip angle of the imaging sequence which has been shown to improve myocardial nulling and effectively reduced ghosting artifacts in the 3D LGE images [20]. Finally, the prolonged acquisition times required for high-resolution 3 D LGE imaging are accompanied by a progressive decline in contrast agent concentration in the blood pool. As a result, the ideal TI to null the normal myocardium gradually increases. This limitation can be addressed by using a steadily increasing inversion time that optimizes tissue nulling for improved contrast [21].

While 3 D LGE imaging has become the reference for atrial scar imaging, it has not been widely adapted for $\mathrm{LV}$ scar imaging due to the unpredictable scan time related to respiratory motion gating. To address the relatively long scan time and associated washout of
GBCA, single breath-hold 3 D LGE sequences have been proposed with and without $[22,23]$ undersampled reconstruction. While these approaches have provided promising results, they have not replaced 2 D LGE MRI due to their lower spatial resolution and lower scar to myocardium contrast. The main limitations of all $3 \mathrm{D}$ implementations have been the prolonged and unpredictable scan time and ghosting artifacts from unsuppressed subcutaneous fat signal where shimming is less effective.

\section{Fat/water separation methods}

Although fat suppression in 2D LGE MRI is not very common, it is crucial in free-breathing 3D LGE to minimize ghosting artifacts from subcutaneous fat which can be pronounced in patients with irregular and/or deep breathing. Initial free-breathing navigatorgated 3D LGE implementations employed a frequency selective fat saturation pulse to suppress epicardial, pericardial, and subcutaneous fat. Those sequences have been very effective on $1.5 \mathrm{~T}$ MRI scanners. However, at a higher field strength, fat suppression can sometimes be suboptimal due to larger $\mathrm{B}_{0}$ inhomogeneity. This can cause unwanted ghosting artifacts from subcutaneous fat, which are more pronounced in LGE scans due to the relatively low overall signal to noise ratio (SNR). An alternative method for dealing with fat-related artifacts is the use of water-fat separation using the 2- or 3-point Dixon method, which allows the effective separation of the water from the fat signal, and which is relatively 


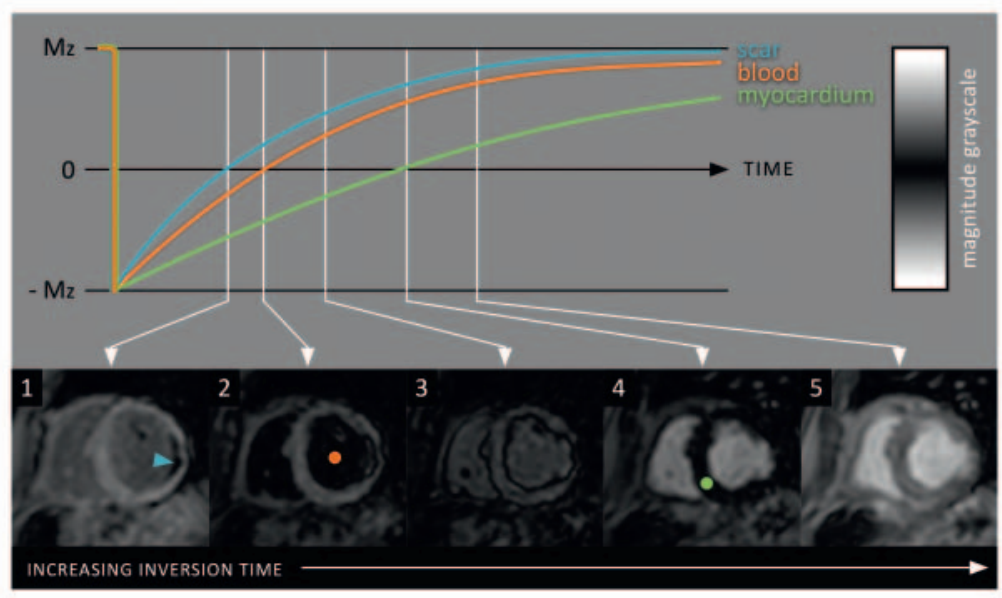

- Fig. 3 Example of a "Look-Locker" or scout scan that provides a series of low-resolution images with increasing inversion time (TI). After injection of the contrast agent, the scar tissue and blood pool have a shorter $\mathrm{T}_{1}$ relaxation time compared to the normal myocardium, leading to a faster recovery of the longitudinal magnetization (Mz). Therefore, the scar tissue (cyan curve) reaches the zero-magnetization level first, shown as a black appearance in the magnitude image (cyan arrowhead in image 1). Soon after, the blood pool follows (orange curve + dot in image 2 ), and, finally, the normal myocardium (green curve + dot in image 4). In this example, the TI that corresponds to image 4 should be set for conventional myocardium-nulled (bright-blood) LGE.

- Abb. 3 Beispiel eines „Look-Locker“-Scans, der eine Reihe von Bildern mit niedriger Auflösung mit zunehmender Inversionszeit (TI) liefert. Nach Injektion des Kontrastmittels haben das Narbengewebe und der Blutpool im Vergleich zum gesunden Myokard eine kürzere $T_{1}$-Relaxationszeit, was zu einer schnelleren Erholung der Längsmagnetisierung (Mz) führt. Daher erreicht das Narbengewebe (cyanfarbene Kurve) zuerst das Nullmagnetisierungsniveau, was als schwarze Erscheinung auf dem Magnitudenbild angezeigt wird (cyanfarbene Pfeilspitze in Bild 1). Bald darauf folgt der Blutpool (orange Kurve und Punkt in Bild 2) und schließlich das normale Myokard (grüne Kurve und Punkt in Bild 4). In diesem Beispiel sollte die TI, die Bild 4 entspricht, für das konventionelle („bright-blood“) LGE eingestellt werden.

robust with respect to $B_{0}$ inhomogeneity at a higher field strength ( $\triangleright$ Fig.6). The Dixon water-fat separation methods acquire both an in-phase and out-of-phase image, where the water and fat signals are either in- or out-of-phase. Several reconstruction methods have been proposed (e. g., IDEAL [24], graph cut [25]), which allow for separation of the water and fat signals and consequently generation of a water-only and a fat-only image or volume. An added benefit of Dixon-based water-fat separation is the increased SNR due to the acquisition of two or three echoes. Moreover, Dixon LGE allows the detection of intramyocardial fatty infiltration, which is considered a risk factor for future cardiac events. The fat image also has been used to estimate respiratory motion, which can be beneficial, as the water signal is typically suppressed by the initial inversion pulse of the $3 \mathrm{D}$ LGE sequence.

\section{Motion correction methods}

As mentioned previously, free-breathing 3 D LGE MRI requires respiratory motion correction. Initial approaches employing respiratory navigators suffer from long and unpredictable scan times. For these reasons, self-navigation [26] and image-navigation $[27,28]$ approaches have been proposed to enable $100 \%$ scan efficiency without the need for data rejection. The self-navigation approach proposed by Rutz et al. demonstrated improved myocardial border sharpness in comparison to the standard clinical $2 \mathrm{D}$ LGE sequence [26]. Image navigators in concert with non-rigid motion correction, a 2-point Dixon readout, and undersampled low-rank patch-based multi-contrast reconstruction (HD-PROST) enabled scar imaging with high spatial resolution ( $1.3 \mathrm{~mm}$ isotropic) in a scan time of approximately 8 minutes with good agreement with breath-hold 2 D LGE MRI [28]. Motion tracking was facilitated by using the out-of-phase image navigator, which provided the best motion tracking fidelity in comparison to the in-phase, water-only, and fat-only navigator images. The 3 D LGE imaging sequence was also evaluated in patients with an atrial scar and showed similar image quality compared to he diaphragmatic navigator (dNAV) technique, however, with a lower scan time compared to the dNAV $(4.5 \pm 1.2$ min vs. $10.9 \pm 3.9 \mathrm{~min}, \mathrm{p}<0.0001)$ [29].

\section{Dark-blood methods}

Although LGE can adequately distinguish hyperenhanced scar regions from normal myocardium, conventional (myocardiumnulled) LGE has its limitations. Due to the almost equally bright signal of the adjacent blood pool, detection of these small areas of ischemic scar is challenging. Even when successfully detecting such areas, identifying the exact scar-blood border remains difficult. Already more than 15 years ago, advances were made to increase scar-to-blood contrast using various additional magnetization preparation mechanisms. Over the years, numerous new LGE approaches have emerged to improve subendocardial scar conspicuity ( $\triangleright$ Fig. 7) [108]. Although these methods achieve superior scar-to-blood contrast compared to conventional LGE, the majority require additional magnetization preparation 


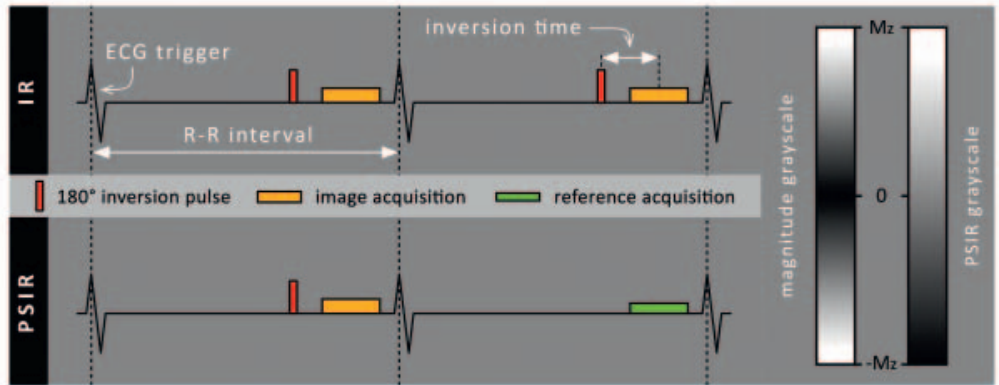

- Fig. 4 Phase-sensitive inversion-recovery (PSIR) versus standard inversion-recovery (IR): whereas a 180 degrees inversion pulse is applied in IR every heartbeat, this same pulse is applied only once every two heartbeats in PSIR. In the second heartbeat, a low flip angle (5 vs. 25 degrees) reference acquisition is performed at exactly the same trigger delay time as the actual image acquisition (in the first heartbeat). This reference acquisition helps to distinguish between positive and negative longitudinal magnetization (Mz) levels and enables the construction of the additional corrected real (PSIR) image. This resulting PSIR image uses a different grayscale compared to the conventional magnitude grayscale used for standard IR LGE. Negative magnetization levels appear darkest, nulled magnetization levels appear mid-gray, and positive magnetization levels appear bright.

- Abb. 4 Phasen-sensitive Inversion-Recovery (PSIR) versus Standard Inversion-Recovery (IR): Während in der IR bei jedem Herzschlag ein 180-GradInversionspuls appliziert wird, wird dieser Impuls in der PSIR nur einmal alle zwei Herzschläge appliziert. Beim zweiten Herzschlag wird eine Referenzaufnahme mit niedrigem Flip-Winkel (5 vs. 25 Grad) mit genau derselben Trigger-Verzögerung wie die eigentliche Bildaufnahme (des ersten Herzschlags) aufgenommen. Diese Referenzaufnahme hilft zwischen positiver und negativer Längsmagnetisierung (Mz) zu unterscheiden und ermöglicht die Konstruktion eines zusätzlichen korrigierten realen (PSIR-) Bildes. Dieses resultierende PSIR-Bild verwendet eine andere Grauskala als die herkömmliche Grauskala, die für den Standard verwendet wird. Negative Längsmagnetisierung wird am dunkelsten, genullte Längsmagnetisierung mittelgrau und positive Längsmagnetisierung hell dargestellt.
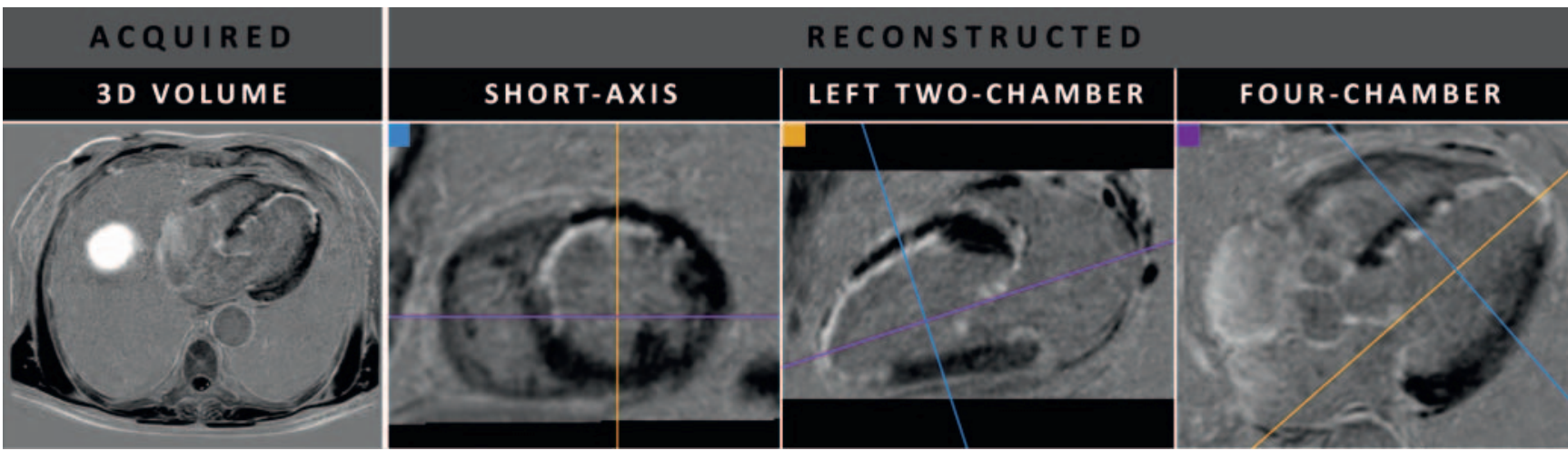

- Fig. $53 \mathrm{D}$ late gadolinium enhancement imaging with high isotropic resolution $(1.6 \times 1.6 \times 1.6 \mathrm{~mm}$ acquired) in a patient with myocardial infarction. The high isotropic resolution enables the use of multiplanar reformatting (MPR), allowing for the selection of desired imaging planes after acquisition. Note that the three cardiac imaging planes (right) are all reconstructed from the same $3 \mathrm{D}$ volume acquired as transverse slices (left).

- Abb.5 3D-Bildgebung mit Late Gadolinium Enhancement mit hoher isotroper Auflösung (1.6×1.6×1.6 mm erworben) bei einem Patienten mit Myokardinfarkt. Die hohe isotrope Auflösung ermöglicht multiplanare Reformationen (MPR), was die Auswahl der gewünschten Bildgebungsebenen nach der Aufnahme ermöglicht. Die drei kardialen Bildgebungsebenen (rechts) wurden alle aus demselben 3D-Volumen rekonstruiert, das als transversales Schichtpaket (links) erfasst wurde.

schemes, including $T_{2}$ preparation [30-33], magnetization transfer [34, 35], spin-locking [35], and the utilization of multiple inversion pulses [36, 37]. These additional schemes, however, require adjustments to the MRI system software and/or configuration, optimizations for new sequence and patient-specific parameters, and additional training for radiographers, radiologists, and cardiologists, thus hampering their introduction into routine clinical practices. Alternatively, a dark-blood LGE method that achieves increased scar-to-blood contrast without using additional magnetization preparation (blood-nulled PSIR LGE) was proposed, making it readily and widely available in every clinical routine setting $[38,39]$. While most novel dark-blood methods have been compared with conventional LGE, only flow-independent darkblood delayed enhancement (FIDDLE) and blood-nulled PSIR LGE have been validated against histology $[34,57]$. Both methods demonstrated superior visualization and quantification of ischemic scar patterns compared to the current in-vivo reference standard; conventional myocardium-nulled LGE. 

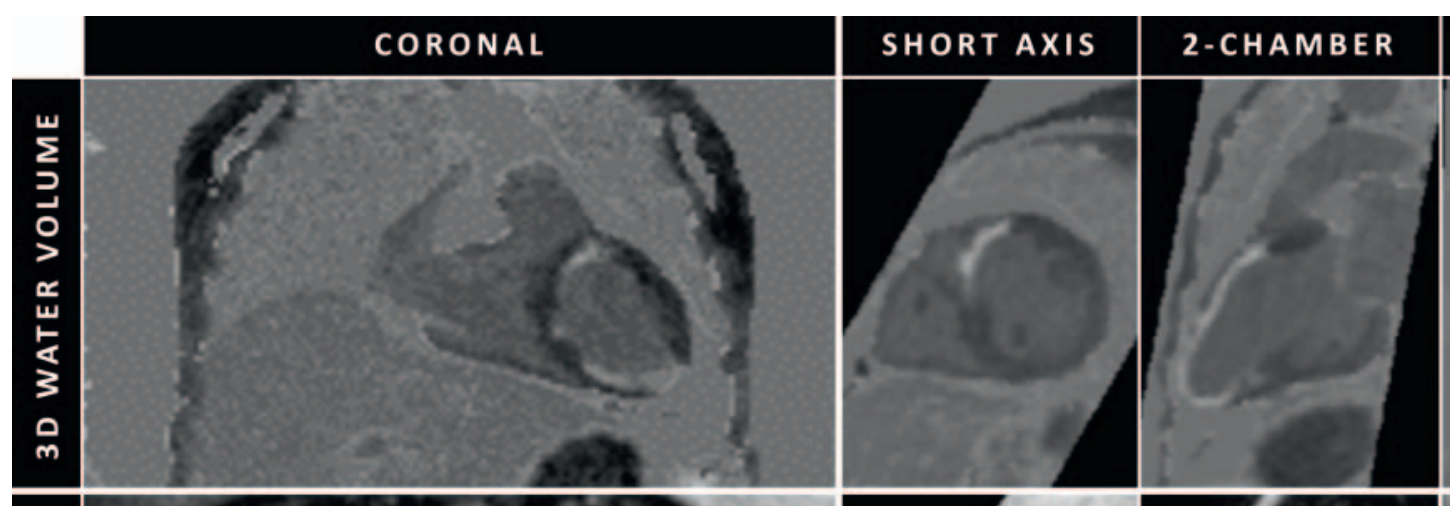

4-CHAMBER
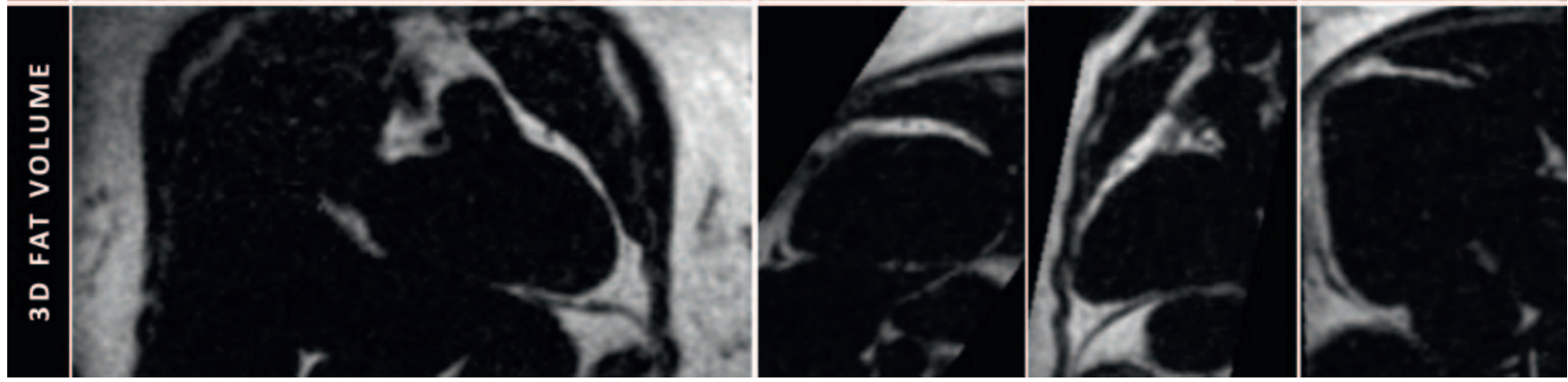

- Fig. 6 Water/fat-separated 3D LGE images acquired used the 2-point Dixon method in a patient with myocardial infarction. After acquiring the inand out-of-phase images, water/fat separation can be performed to obtain a water- and fat-only volume (coronal view shown). The high-resolution 3 D acquisition enables reconstruction of every imaging plane after acquisition (see also $>$ Fig. 5), with the short-axis, 2-chamber and 4-chamber views being shown here. Image navigation was used to correct for respiratory motion. The blood-nulled PSIR LGE approach was used to obtain dark-blood contrast.

- Abb. 6 Wasser/Fett-getrennte 3D LGE-Bilder, die mit der 2-Punkt-Dixon-Methode bei einem Patienten mit Myokardinfarkt aufgenommen wurden. Nach dem Erfassen der „In-“ und „Out-of-Phase“-Bilder kann eine Wasser-Fett-Trennung durchgeführt werden, um ein reines Wasser- und Fettbild zu erhalten (koronare Ansicht). Die hochauflösende 3D-Akquisition ermöglicht die Rekonstruktion jeder Bildebene nach der Aufnahme (siehe auch Abb. 5), wobei hier die Kurzachsen-, 2-Kammer- und 4-Kammer-Ansicht gezeigt wird. Die Atembewegung wurde durch die Navigator-Technik korrigiert. Die blut-genullte PSIR LGE-Methode wurde verwendet um einen „dark-blood“ Kontrast zu erhalten.

\section{Scar quantification methods}

For most clinical indications, visual assessment of LGE images is sufficient and quantitative analysis is primarily performed to measure LGE extent for research purposes. By today, no method for LGE quantification is universally accepted. Several techniques have been proposed including manual contouring, semi-automated approaches using signal intensity thresholds between two to six times the standard deviation from the normal myocardium, non-binary techniques, and the full width at half maximum (FWHM) approach [40, 41]. While manual contouring methods are time-consuming, semi-automated approaches require the definition of regions of interest in the remote and/or enhanced myocardium. Notably, different methods lead to somewhat varying results in regard to reproducibility and histology as the reference standard [42]. Therefore, accurate and objective LGE quantification remains a research tool without current clinical implementation.

\section{Diagnostic value}

The LGE technique has dramatically changed the role of CMR in the evaluation of cardiomyopathies as it is able to differentiate between ischemic and non-ischemic cardiomyopathies by identifying specific patterns of LGE [43]. Ischemic cardiomyopathies are characterized by an LGE pattern that involves the subendocardium and can extend up to the epicardium to form a transmural scar (so-called "wave front phenomenon" of ischemic cell death) in a territory of a coronary artery ( $\bullet$ Fig. 8). LGE imaging also provides insight into irreversible damage of the microvascular circulation by visualizing a microvascular obstruction (MVO), also known as the no-reflow phenomenon ( $\bullet$ Fig. 9). MVO can be identified as low or absent signal areas in LGE images and is typically located within the central portions of the infarcted tissue.

In contrast, non-ischemic cardiomyopathies are characterized by mid-wall, epicardial, or global endocardial LGE. Around $30 \%$ of patients with heart failure caused by dilated cardiomyopathy (DCM) present with mid-wall enhancement predominantly in the interventricular septum [44, 45]. Beside patients with heart failure, LGE - in conjunction with other anatomic and functional CMR parameters - is an incremental diagnostic tool for the assessment of various acute and chronic cardiomyopathies. LGE is a cornerstone technique to identify focal areas of myocardial injury - beside evidence for myocardial edema, the major criteria for the detection of acute myocarditis in the recently updated Lake Louise criteria [46]. Myocarditis typically affects the epicar- 


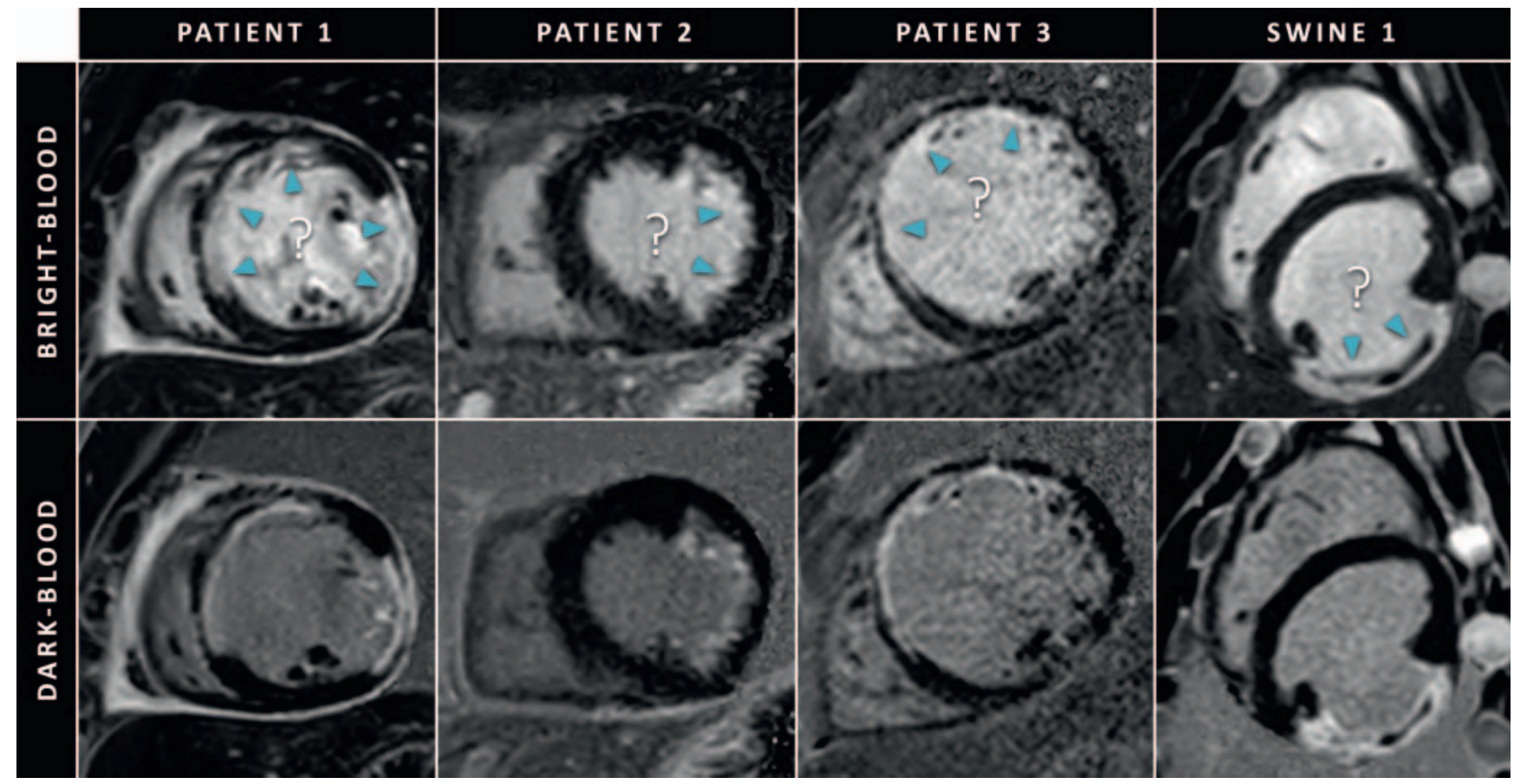

- Fig. 7 Short-axis LGE images of three patients and one swine with (suspicion of) myocardial infarction acquired using conventional bright-blood LGE (top row) and dark-blood LGE (bottom row). Due to the almost equally high signal of the blood pool, conventional LGE suffers from poor scar-to-blood contrast which hampers the detection and delineation of enhanced regions (cyan arrowheads). Note that these indicated regions can be accurately visualised using dark-blood LGE. The shown dark-blood LGE images were acquired using the blood-nulled PSIR LGE approach [38].

- Abb.7 Kurzachsen-LGE-Bilder von drei Patienten und einem Schwein mit (Verdacht auf) Myokardinfarkt, aufgenommen mit konventionellen „bright-blood“ LGE (obere Reihe) und „dark-blood“ LGE (untere Reihe). Aufgrund des fast gleich hohen Signals des Blutpools leidet das konventionelle LGE unter einem schlechten Narben-zu-Blut-Kontrast, der die Erkennung und Abgrenzung von kontrastmittelaufnehmenden Abschnitten (cyanfarbene Pfeilspitzen) limitiert. Diese Abschnitte können mit dem „dark-blood“ LGE akkurat abgegrenzt werden. Die gezeigten „dark-blood“ LGE-Bilder wurden mit dem blut-genullten PSIR-LGE-Ansatz aufgenommen [38].

dium with variable extension to the midmyocardial wall and sparing of the subendocardial portions of the myocardium. A dominance in the lateral and inferolateral wall is frequently described [47]. In more chronic cardiomyopathies such as hypertrophic cardiomyopathy (HCM) and amyloidosis, LGE can be used to identify foci of diffuse scarring. The pattern of LGE in HCM is typically patchy and predominantly located in hypertrophic parts of the myocardium and sometimes within a mid-wall location that involves the junction zones between the left and right ventricle as a sign of myocardial disarray. Amyloidosis, a systemic disease with infiltration of various organs including the heart, can be diagnosed by CMR using specific patterns of functional and structural changes including myocardial hypertrophy, thickened interatrial septum and bi-atria dilation [48]. In addition to those anatomical changes, LGE imaging often demonstrates a unique appearance in amyloidosis, as wash-in and wash-out kinetics of gadolinium are dramatically changed by accumulation of amyloid fibrils in the myocardial interstitium. This results in the inability to properly null the myocardium using TI scouts, leading to a zebra-striped appearance with global subendocardial enhancement of LV and RV, and atrial walls, and a relative dark appearing blood pool, indicating high myocardial contrast uptake and fast blood pool washout [49]. Around $50 \%$ of patients with valvular heart disease, such as severe aortic stenosis, present with evidence of LGE [50]. In aortic stenosis, LGE is a result of chronic pressure overload of the left ventricle [51]. Both infarct and non-infarct-like patterns can be present in aortic stenosis. However, due to the absence of randomized clinical trials using LGE in valvular heart disease, the assessment of myocardial fibrosis by LGE is not included in the routine evaluation of patients with severe aortic stenosis [50]. A pictorial overview of LGE patterns of non-ischemic cardiomyopathies is provided in $\mathbf{r i g} \mathbf{~} \mathbf{1 0}$.

Irrespectively of the etiology of myocardial disease, several studies demonstrated that distinct patterns of LGE correspond to focal fibrosis at histopathology/autopsy in human [52-56] and animal studies $[2,57]$ in a wide range of clinical scenarios.

\section{Prognostic value}

LGE is the current CMR standard to assess myocardial viability in ischemic cardiomyopathy. LGE allows the detection of even small subendocardial infarcts due to its superior spatial resolution, which may be missed by other imaging techniques with lower spatial resolution such as single-photon emission computed tomography [58-60]. LGE is also a reliable tool for the assessment of myocardial viability and the likelihood of recovery after revascularization [61]. Kim et al. could initially demonstrate an inverse 


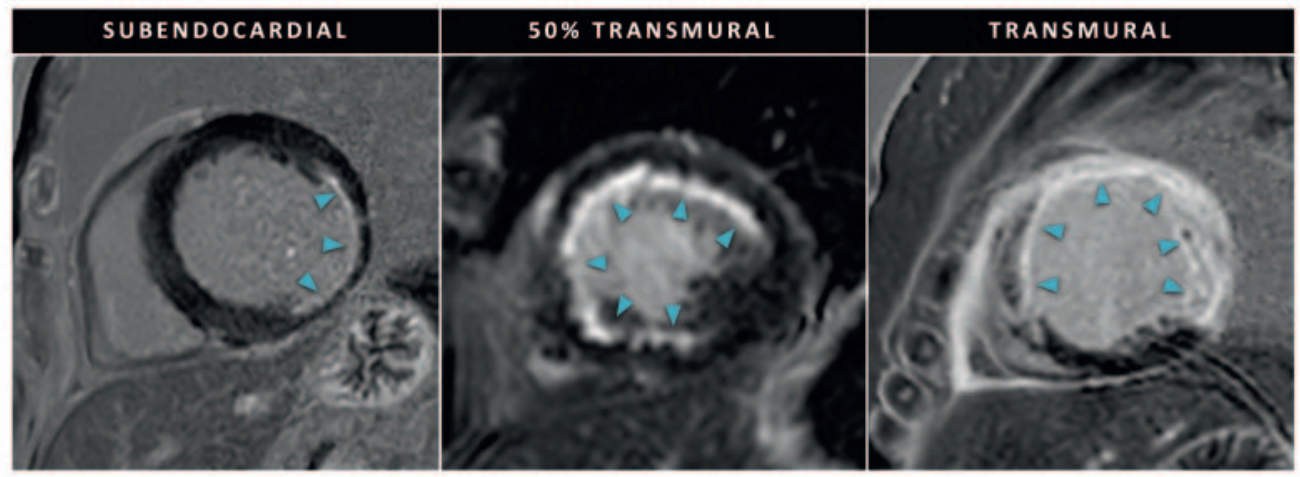

- Fig. 8 Short-axis LGE images of three patients with myocardial infarction showing various degrees of scar transmurality. The scar regions are indicated using cyan arrowheads.

- Abb. 8 Kurzachsen-LGE-Bilder von drei Patienten mit Myokardinfarkt, die verschiedene Grade der Narben-Transmuralität zeigen. Die Narbenregionen sind mit cyanfarbenen Pfeilspitzen gekennzeichnet.

relation between the transmurality of LGE and the recovery of segmental contractile function after revascularization [62]. A transmurality of $<50 \%$ has been shown to predict a very high likelihood for functional recovery, while functional improvement in segments with scar transmurality of $>50 \%$ was only $8 \%$. Various studies have confirmed these results in both acute and chronic infarct settings [63, 64].

The assessment of the extent of LGE in acute myocardial infarction has significant prognostic value. A meta-analysis incorporating 10 randomized trials with 2632 patients with acute myocardial infarction demonstrated that a $5 \%$ increase in infarct size correlates to a $20 \%$ increase in rates for all-cause mortality and heart failure-related hospitalization [65]. In addition, LGE extent was a strong predictor of major adverse cardiovascular events (MACE), independent of LV function [61]. However, MVO was a stronger independent predictor of LV dysfunction and post-infarct complications compared to LGE extent $[66,67]$. Infarct size and MVO outperformed clinical risk scores and LV ejection fraction for the prediction of adverse events $[67,68]$. MVO most likely represents irreversible tissue destruction and clinically relevant reperfusion injury, which are both parameters that have been linked to negative LV remodeling [69]. Hence, besides quantifying the size of the infarct, the evaluation of vascular integrity may have a relevant role for prognosis estimation in acute myocardial infarction. In chronic ischemic heart disease, LGE is a stronger predictor of clinical outcome than contractile reserve $[70,71]$.

The presence of LGE in patients with non-ischemic myocardial injury and cardiomyopathies is strongly associated with poor prognosis, including increased risk of all-cause mortality, heart failure hospitalization, and sudden cardiac death [72].

In DCM, LGE is associated with abnormal function and serves as a potential substrate for re-entrant ventricular arrhythmias [73]. Several studies have evaluated the prognostic implications of LGE in DCM patients [44, 74-76]. Recently, a large, multi-institutional study has followed 1672 patients with DCM over a median of 2.3 years and found a 1.5 -fold increased risk of LGE for all-cause mortality, heart transplantation, or left ventricular assist device implantation [77]. In addition, LGE identifies patients who may not respond optimally to medical therapies, and therefore might play a role as a gatekeeper for intensified medical treatments or procedures such as ICD implantation [78]. However, there are currently no clinical guidelines supporting LGE as a relevant criterion for clinical decision-making and therapy indication.

In myocarditis, LGE has been identified as the best indicator of all-cause mortality in a series of 202 consecutive biopsy-proven viral myocarditis patients. Over a time period of 4.7 years, the presence of LGE increased all-cause and cardiac mortality by 8.4and 12.8-fold, independent of clinical symptoms [79]. Furthermore, other larger prospective studies demonstrated that the location and extent of LGE were independent predictors of adverse cardiac events [80-82].

Several studies have examined the relationship between the presence of LGE and adverse outcomes in HCM. For example, the presence of LGE increased the risk for all-cause and cardiac mortality 5.5- and 8-fold over 3 years in $243 \mathrm{HCM}$ patients [83]. A recent meta-analysis including 2993 patients with a follow-up over three years identified LGE as a powerful predictor of sudden cardiac death, all-cause mortality, and cardiovascular mortality [84]. In addition, this and another meta-analysis could also link the extent of LGE to a continuously increased risk of adverse events with higher amounts of scarring $[84,85]$.

The prognosis of amyloidosis is clearly influenced by the presence and severity of cardiac involvement [45]. The diagnostic performance of CMR and LGE has been well validated in cardiac amyloidosis. However, its prognostic value is controversial. Maceira et al. as well as Ruberg et al. could not demonstrate a relevant influence of the presence and extent of LGE on the short-term prognosis of cardiac amyloid patients in smaller study cohorts $[48,86]$. Another study by Mekinian et al. could demonstrate a relationship between LGE and markers of ventricular dysfunction but failed to demonstrate the incremental prognostic value on mortality after the adjustment for confounding para- 


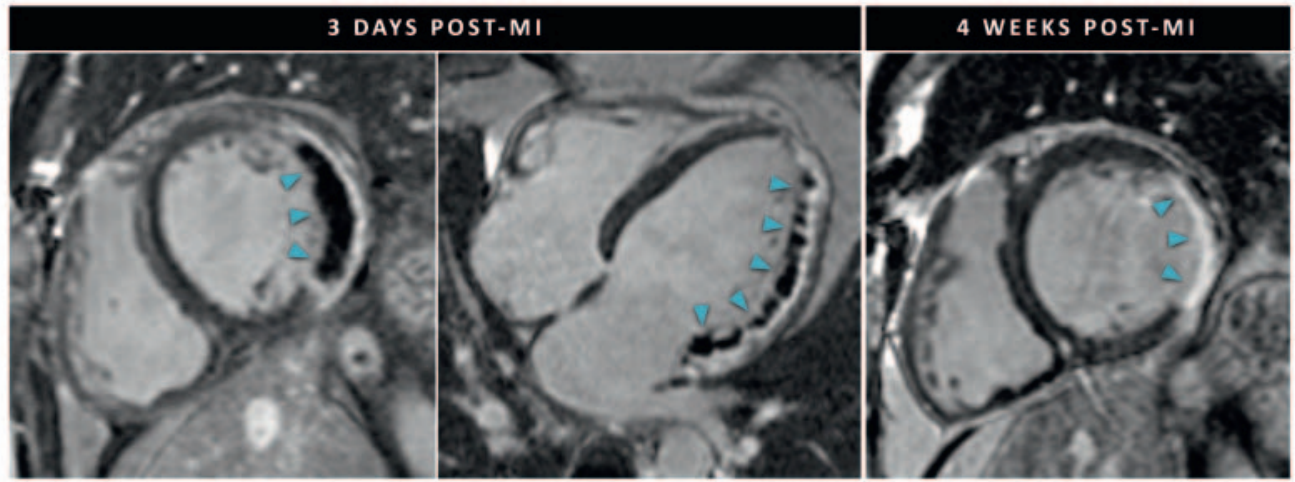

- Fig. 9 LGE images in a case of acute myocardial infarction (MI). The left two LGE images show a short-axis and four-chamber view 3 days post-MI (symptom to recanalization time $>24$ hours). Extensive regions of microvascular obstruction (MVO) can be observed as dark areas within the enhanced areas. The right LGE image shows a short-axis view 4 weeks post-MI. Left ventricular remodeling can be observed with shrinkage of the infarct area, replacement fibrosis, and an increase of the end-diastolic left-ventricular volume (cine imaging, not shown). The cyan arrowheads indicate the affected area.

- Abb.9 LGE-Bilder bei einem Patienten mit akutem Myokardinfarkt (MI). Die beiden linken LGE-Bilder zeigen eine Kurzachsen- und Vierkammeransicht 3 Tage nach MI (Zeit von Symptom bis Rekanalisation > 24 Stunden). Ausgedehnte Bereiche mikrovaskulärer Obstruktion (MVO) können als dunkle Bereiche innerhalb der kontrastmittelaufnehmenden Abschnitte abgegrenzt werden. Das rechte LGE-Bild zeigt eine Kurzachsenansicht 4 Wochen nach MI. Das linksventrikuläres Remodeling führt zu einer Schrumpfung des Infarktbereichs, Gewebe-Ersatz-Fibrosierung und einer Zunahme des enddiastolischen linksventrikulären Volumens (Cine-Bildgebung, nicht gezeigt). Die cyanfarbenen Pfeilspitzen zeigen den betroffenen Bereich an.

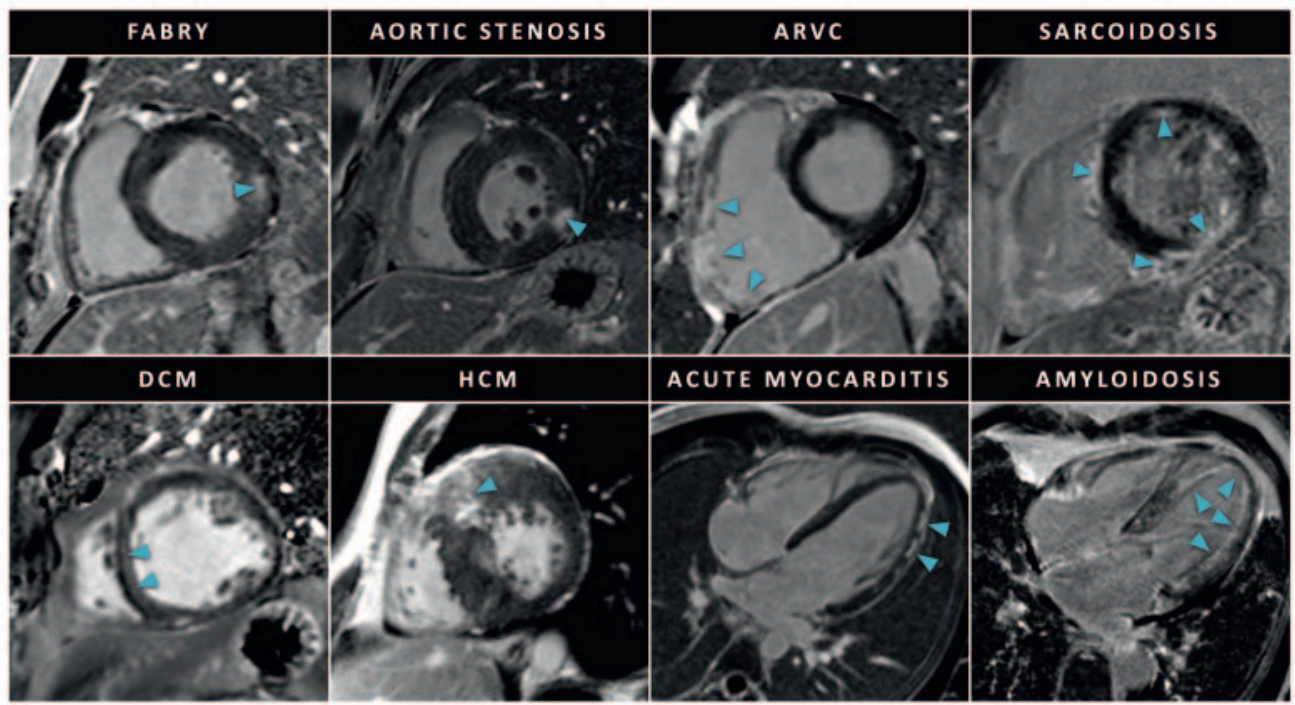

- Fig. 10 Case examples of various non-ischemic cardiomyopathies. The scar regions are indicated by cyan arrowheads. ARVC: arrhythmogenic right-ventricular cardiomyopathy; DCM: dilated cardiomyopathy; HCM: hypertrophic cardiomyopathy.

- Abb.10 Fallbeispiele verschiedener nicht-ischämischer Kardiomyopathien. Die Narbenregionen sind durch cyanfarbene Pfeilspitzen gekennzeichnet. ARVC: arrhythmogene rechtsventrikuläre Kardiomyopathie; DCM: dilatative Kardiomyopathie; HCM: hypertrophe Kardiomyopathie.

meters [87]. Conversely, other studies with larger study populations identified LGE to be the strongest predictor of all-cause mortality [88-90]. These conflicting findings may be explained by the diffuse nature of amyloid as a disease, as LGE may miss diffuse changes of the myocardium.
Valvular heart disease such as aortic stenosis is an important and increasing public health problem, in particular with increasing prevalence in aging western population [91]. LGE imaging has been used for risk prediction in patients with aortic stenosis [92-94]. In aortic stenosis, fibrosis on LGE imaging is a useful biomarker of LV remodeling, and its presence is associated with a 
worse long-term outcome after aortic valve intervention [94]. A systematic review and meta-analysis indicate that LGE is a powerful prognostic marker, conveying > 2-fold higher risk of all-cause mortality in patients with aortic stenosis, even after adjusting for baseline characteristics [50].

Recently, an "umbrella" review of meta-analyses in various heart diseases using 33 meta-analyses demonstrated the highly suggestive evidence for a prognostic role of LGE in heart disease, which may be used to impact guidelines and therapeutic strategies in the future [95].

\section{Discussion}

As early as 1984, GBCAs have been used to study differences in normal and infarcted myocardium using MRI [96]. Ever since, the role of LGE imaging for the evaluation of myocardial viability has been extensively investigated in both animal models [2, 97, 98] and patient studies [99-101]. As of today, LGE imaging is the main component of cardiac MRI protocols on both $1.5 \mathrm{~T}$ and $3 \mathrm{~T}$ systems [102] and is performed in clinical routine settings all over the world on a daily basis.

As the use of LGE imaging has matured and the range of applications has broadened, the demand for increased resolution has grown and the need for improved contrast increased. In fact, for the assessment of thin-walled structures with a thickness of just a few millimeters, such as the atria and right ventricles, smaller voxels are required to reduce partial volume effects, while improved scar-to-blood contrast is crucial to detect small subendocardial lesions. Even though these demands have been partly addressed by recent developments such as the dark-blood and high-resolution $3 \mathrm{D}$ techniques described earlier, these have not yet been widely implemented in clinical protocols outside of academic centers.

Despite the promising diagnostic and prognostic implications, LGE imaging has a limited capability to detect diffuse myocardial involvement, as myocardial enhancement must be compared to normal reference tissue. Mapping techniques, such as $T_{1}$ and $T_{2}$ mapping, however, measure intrinsic tissue properties, and therefore do not rely on reference tissue. Thus, mapping techniques are able to identify diffuse processes, such as inflammation in myocarditis or fibrosis in dilated cardiomyopathy, and have emerged as clinical tools for myocardial characterization [103, 104]. In the specific context of LGE imaging, $T_{1}$ mapping has become a promising alternative technique to provide myocardial characterization.

On the other hand, LGE will play an increasingly important future role in the detection and assessment of atrial fibrosis, a common pathophysiological factor to the onset and maintenance of atrial fibrillation. The combination of high isotropic resolution and optimized dark-blood contrast is a promising approach to tackle the current problems with the thin atrial wall and poor scar-to-blood contrast. The use of high-resolution 3 D LGE may be evaluated for various indications, ranging from predicting the risk of cardiovascular events in patients with atrial fibrillation and predicting post-ablation arrhythmia recurrence, to guiding atrial fibrillation ablations and mapping post-ablation scar patterns to guide potential repeat procedures. High-resolution 3 D LGE, however, may also prove beneficial for assessing the larger ventricles. Potential clinical benefits that should be evaluated include the improved ability to detect microstructural fibrosis which is important for patients with presumed idiopathic ventricular fibrillation and the ability to perform accurate multiplanar reconstructions for the assessment of papillary muscle scar. This may pave the way for improved diagnostic accuracy and prognosis but also plays an important role in the work-up towards personalized treatment of patients with (supra)ventricular tachyarrhythmias.

As the number of patients with cardiac devices is increasing, future research may focus on LGE techniques that are robust for local disturbances in the main magnetic field caused by such devices. The use of wideband LGE sequences may help minimize image artifacts caused by these disturbances at both 1.5 T and $3 \mathrm{~T}[105,106]$. However, since clinical evidence is limited, additional research is required to enable widespread clinical adoption.

In addition, the recent introduction of compressed sensing by the major vendors enabled widespread use of sparse imaging techniques, achieving acceleration factors that have not previously been possible to attain with parallel imaging alone. Artificial intelligencebased reconstruction techniques may be used to further push the use of compressed sensing methods [107], achieving high-resolution $3 \mathrm{D}$ LGE acquisitions of the entire heart in a matter of minutes.

In conclusion, LGE imaging remains the current noninvasive reference standard for the assessment of myocardial viability. Improvements in spatial resolution, scar-to-blood contrast, and water/fat-separated imaging further strengthened this position. LGE will play an increasingly important role in the diagnosis, prognosis, and treatment planning of patients with (supra)ventricular cardiac arrhythmias.

\section{Conflict of Interest}

The authors declare that they have no conflict of interest.

\section{References}

[1] Kramer CM, Barkhausen J, Bucciarelli-Ducci C et al. Standardized cardiovascular magnetic resonance imaging (CMR) protocols: 2020 update. J Cardiovasc Magn Reson 2020; 22: 17

[2] Kim R], Fieno DS, Parrish TB et al. Relationship of MRI delayed contrast enhancement to irreversible injury, infarct age, and contractile function. Circulation 1999; 100: 1992-2002

[3] Simonetti OP, Kim R], Fieno DS et al. An improved MR imaging technique for the visualization of myocardial infarction. Radiology 2001; 218: 215-223

[4] Neilan TG, Coelho-Filho OR, Danik SB et al. CMR quantification of myocardial scar provides additive prognostic information in nonischemic cardiomyopathy. JACC Cardiovasc Imaging 2013; 6: 944-954

[5] Bojer AS, Sorensen MH, Vejlstrup N et al. Distinct non-ischemic myocardial late gadolinium enhancement lesions in patients with type 2 diabetes. Cardiovasc Diabetol 2020; 19: 184

[6] Oakes RS, Badger T], Kholmovski EG et al. Detection and quantification of left atrial structural remodeling with delayed-enhancement magnetic resonance imaging in patients with atrial fibrillation. Circulation 2009; 119: $1758-1567$ 
[7] Marrouche NF, Wilber D, Hindricks G et al. Association of atrial tissue fibrosis identified by delayed enhancement MRI and atrial fibrillation catheter ablation: The decaaf study. JAMA 2014; 311: 498-506

[8] Dickfeld T, Kato R, Zviman M et al. Characterization of radiofrequency ablation lesions with gadolinium-enhanced cardiovascular magnetic resonance imaging. J Am Coll Cardiol 2006; 47: 370-378

[9] Akoum N, Wilber D, Hindricks G et al. MRI assessment of ablation-induced scarring in atrial fibrillation: Analysis from the decaaf study. J Cardiovasc Electrophysiol 2015; 26: 473-480

[10] Fochler F, Yamaguchi T, Kheirkahan M et al. Late gadolinium enhancement magnetic resonance imaging guided treatment of post-atrial fibrillation ablation recurrent arrhythmia. Circ Arrhythm Electrophysiol 2019; 12: e007174

[11] Kirstein B, Morris A, Baher A et al. Magnetic resonance imaging-guided cryoballoon ablation for left atrial substrate modification in patients with atrial fibrillation. J Cardiovasc Electrophysiol 2020; 31: 1587-1594

[12] Mahrholdt H, Wagner A, Judd RM et al. Assessment of myocardial viability by cardiovascular magnetic resonance imaging. Eur Heart J 2002; 23: 602-619

[13] Kellman P, Arai AE. Cardiac imaging techniques for physicians: Late enhancement. J Magn Reson Imaging 2012; 36: 529-542

[14] Look DC, Locker DR. Time saving in measurement of NMR and EPR relaxation times. Rev Sci Instrum 1970; 41: 250-251

[15] Kim RJ, Shah DJ, Judd RM. How we perform delayed enhancement imaging. J Cardiovasc Magn Reson 2003; 5: 505-514

[16] Kellman P, Arai AE, McVeigh ER et al. Phase-sensitive inversion recovery for detecting myocardial infarction using gadolinium-delayed hyperenhancement. Magn Reson Med 2002; 47: 372-383

[17] Saranathan M, Rochitte CE, Foo TK. Fast, three-dimensional free-breathing MR imaging of myocardial infarction: A feasibility study. Magn Reson Med 2004; 51: 1055-1060

[18] Spuentrup E, Buecker A, Karassimos E et al. Navigator-gated and real-time motion corrected free-breathing MR imaging of myocardial late enhancement. Rofo 2002; 174: 562-567

[19] Keegan J, Drivas P, Firmin DN. Navigator artifact reduction in threedimensional late gadolinium enhancement imaging of the atria. Magn Reson Med 2014; 72: 779-785

[20] Hu C, Huber S, Latif SR et al. Repairit: Improving myocardial nulling and ghosting artifacts of 3D navigator-gated late gadolinium enhancement imaging during arrhythmia. J Magn Reson Imaging 2019; 49: 688-699

[21] Holtackers RJ, Gommers S, Van De Heyning CM et al. Steadily increasing inversion time improves blood suppression for free-breathing 3D late gadolinium enhancement MRI with optimized dark-blood contrast. Invest Radiol 2021; 56: 335-340

[22] Foo TK, Stanley DW, Castillo E et al. Myocardial viability: Breath-hold 3D MR imaging of delayed hyperenhancement with variable sampling in time. Radiology 2004; 230: 845-851

[23] Dewey M, Laule M, Taupitz M et al. Myocardial viability: Assessment with three-dimensional MR imaging in pigs and patients. Radiology 2006; 239: 703-709

[24] Reeder SB, Hargreaves BA, Yu H et al. Homodyne reconstruction and ideal water-fat decomposition. Magn Reson Med 2005; 54: 586-593

[25] Hernando D, Kellman P, Haldar JP et al. Robust water/fat separation in the presence of large field inhomogeneities using a graph cut algorithm. Magn Reson Med 2010; 63: 79-90

[26] Rutz T, Piccini D, Coppo S et al. Improved border sharpness of postinfarct scar by a novel self-navigated free-breathing high-resolution 3D whole-heart inversion recovery magnetic resonance approach. Int ] Cardiovasc Imaging 2016; 32: 1735-1744

[27] Bratis K, Henningsson M, Grigoratos C et al. Clinical evaluation of threedimensional late enhancement MRI. J Magn Reson Imaging 2017; 45: 1675-1683
[28] Munoz C, Bustin A, Neji R et al. Motion-corrected 3D whole-heart waterfat high-resolution late gadolinium enhancement cardiovascular magnetic resonance imaging. J Cardiovasc Magn Reson 2020; 22: 53

[29] Munoz C, Sim I, Neji R et al. Evaluation of accelerated motion-compensated 3D water/fat late gadolinium enhanced MR for atrial wall imaging. MAGMA 2021; 34: 877-887

[30] Fahmy AS, Neisius U, Tsao CW et al. Gray blood late gadolinium enhancement cardiovascular magnetic resonance for improved detection of myocardial scar. J Cardiovasc Magn Reson 2018; 20: 22

[31] Basha TA, Tang MC, Tsao C et al. Improved dark blood late gadolinium enhancement (DB-LGE) imaging using an optimized joint inversion preparation and T2 magnetization preparation. Magn Reson Med 2018; 79: $351-360$

[32] Kellman P, Xue H, Olivieri L] et al. Dark blood late enhancement imaging. J Cardiovasc Magn Reson 2016; 18: 77

[33] Liu CY, Wieben O, Brittain JH et al. Improved delayed enhanced myocardial imaging with T2-prep inversion recovery magnetization preparation. J Magn Reson Imaging 2008; 28: 1280-1286

[34] Kim HW, Rehwald WG, Jenista ER et al. Dark-blood delayed enhancement cardiac magnetic resonance of myocardial infarction. JACC Cardiovasc Imaging 2018; 11: 1758-1769

[35] Muscogiuri G, Rehwald WG, Schoepf U] et al. T(rho) and magnetization transfer and inversion recovery (TRAMINER)-prepared imaging: A novel contrast-enhanced flow-independent dark-blood technique for the evaluation of myocardial late gadolinium enhancement in patients with myocardial infarction. J Magn Reson Imaging 2017; 45: 1429-1437

[36] Farrelly C, Rehwald W, Salerno M et al. Improved detection of subendocardial hyperenhancement in myocardial infarction using dark bloodpool delayed enhancement MRI. Am J Roentgenol 2011; 196: 339-348

[37] Peel SA, Morton G, Chiribiri A et al. Dual inversion-recovery MR imaging sequence for reduced blood signal on late gadolinium-enhanced images of myocardial scar. Radiology 2012; 264: 242-249

[38] Holtackers RJ, Chiribiri A, Schneider T et al. Dark-blood late gadolinium enhancement without additional magnetization preparation. J Cardiovasc Magn Reson 2017; 19: 64

[39] Holtackers RJ, Van De Heyning CM, Nazir MS et al. Clinical value of darkblood late gadolinium enhancement cardiovascular magnetic resonance without additional magnetization preparation. J Cardiovasc Magn Reson 2019; 21: 44

[40] Mastrodicasa D, Elgavish GA, Schoepf U] et al. Nonbinary quantification technique accounting for myocardial infarct heterogeneity: Feasibility of applying percent infarct mapping in patients. J Magn Reson Imaging 2018. doi:10.1002/jmri.25973

[41] Varga-Szemes A, van der Geest RJ, Schoepf UJ et al. MRI post-processing methods for myocardial infarct quantification. Curr Radiol Rep 2016; 4: 30

[42] Flett AS, Hasleton J, Cook C et al. Evaluation of techniques for the quantification of myocardial scar of differing etiology using cardiac magnetic resonance. JACC Cardiovasc Imaging 2011; 4: 150-156

[43] McCrohon JA, Moon JC, Prasad SK et al. Differentiation of heart failure related to dilated cardiomyopathy and coronary artery disease using gadolinium-enhanced cardiovascular magnetic resonance. Circulation 2003; 108: 54-59

[44] Assomull RG, Prasad SK, Lyne J et al. Cardiovascular magnetic resonance, fibrosis, and prognosis in dilated cardiomyopathy. J Am Coll Cardiol 2006; 48: 1977-1985

[45] Mrsic Z, Mousavi N, Hulten E et al. The prognostic value of late gadolinium enhancement in nonischemic heart disease. Magn Reson Imaging Clin N Am 2019; 27: 545-561

[46] Ferreira VM, Schulz-Menger J, Holmvang G et al. Cardiovascular magnetic resonance in nonischemic myocardial inflammation: Expert recommendations. J Am Coll Cardiol 2018; 72: 3158-3176 
[47] Mahrholdt H, Wagner A, Deluigi CC et al. Presentation, patterns of myocardial damage, and clinical course of viral myocarditis. Circulation 2006; 114: 1581-1590

[48] Maceira AM, Joshi J, Prasad SK et al. Cardiovascular magnetic resonance in cardiac amyloidosis. Circulation 2005; 111: 186-193

[49] Vogelsberg H, Mahrholdt H, Deluigi CC et al. Cardiovascular magnetic resonance in clinically suspected cardiac amyloidosis: Noninvasive imaging compared to endomyocardial biopsy. J Am Coll Cardiol 2008; 51: 10221030

[50] Papanastasiou CA, Kokkinidis DG, Kampaktsis PN et al. The prognostic role of late gadolinium enhancement in aortic stenosis: A systematic review and meta-analysis. JACC Cardiovasc Imaging 2020; 13: 385-392

[51] Barone-Rochette G, Pierard S, De Meester de Ravenstein C et al. Prognostic significance of LGE by CMR in aortic stenosis patients undergoing valve replacement. J Am Coll Cardiol 2014; 64: 144-154

[52] Lima JA, Judd RM, Bazille A et al. Regional heterogeneity of human myocardial infarcts demonstrated by contrast-enhanced MRI. Potential mechanisms. Circulation 1995; 92: 1117-1125

[53] Roberts WC, Siegel RJ, McManus BM. Idiopathic dilated cardiomyopathy: Analysis of 152 necropsy patients. Am J Cardiol 1987; 60: 1340-1355

[54] Moon JC, Reed E, Sheppard MN et al. The histologic basis of late gadolinium enhancement cardiovascular magnetic resonance in hypertrophic cardiomyopathy. J Am Coll Cardiol 2004; 43: 2260-2264

[55] Flett AS, Hayward MP, Ashworth MT et al. Equilibrium contrast cardiovascular magnetic resonance for the measurement of diffuse myocardial fibrosis: Preliminary validation in humans. Circulation 2010; 122: 138144

[56] Miller CA, Naish JH, Bishop P et al. Comprehensive validation of cardiovascular magnetic resonance techniques for the assessment of myocardial extracellular volume. Circ Cardiovasc Imaging 2013; 6: 373-383

[57] Holtackers RJ, Gommers S, Heckman LIB et al. Histopathological validation of dark-blood late gadolinium enhancement MRI without additional magnetization preparation. J Magn Reson Imaging 2022; 55: 190-197

[58] Wagner A, Mahrholdt H, Holly TA et al. Contrast-enhanced MRI and routine single photon emission computed tomography (SPECT) perfusion imaging for detection of subendocardial myocardial infarcts: An imaging study. Lancet 2003; 361: 374-379

[59] Karamitsos TD, Dall'Armellina E, Choudhury RP et al. Ischemic heart disease: Comprehensive evaluation by cardiovascular magnetic resonance. Am Heart J 2011; 162: 16-30

[60] Ibrahim T, Bulow HP, Hackl T et al. Diagnostic value of contrast-enhanced magnetic resonance imaging and single-photon emission computed tomography for detection of myocardial necrosis early after acute myocardial infarction. J Am Coll Cardiol 2007; 49: 208-216

[61] Lee SA, Yoon YE, Kim JE et al. Long-term prognostic value of late gadolinium-enhanced magnetic resonance imaging in patients with and without left ventricular dysfunction undergoing coronary artery bypass grafting. Am J Cardiol 2016; 118: 1647-1654

[62] Kim RJ, Wu E, Rafael A et al. The use of contrast-enhanced magnetic resonance imaging to identify reversible myocardial dysfunction. $\mathrm{N}$ Engl J Med 2000; 343: 1445-1453

[63] Selvanayagam JB, Kardos A, Francis JM et al. Value of delayed-enhancement cardiovascular magnetic resonance imaging in predicting myocardial viability after surgical revascularization. Circulation 2004; 110: 1535-1541

[64] Beek AM, Kuhl HP, Bondarenko O et al. Delayed contrast-enhanced magnetic resonance imaging for the prediction of regional functional improvement after acute myocardial infarction. J Am Coll Cardiol 2003; 42: 895-901

[65] Stone GW, Selker HP, Thiele $\mathrm{H}$ et al. Relationship between infarct size and outcomes following primary $\mathrm{PCl}$ : Patient-level analysis from 10 randomized trials. J Am Coll Cardiol 2016; 67: 1674-1683
[66] Gerber BL, Rochitte CE, Melin JA et al. Microvascular obstruction and left ventricular remodeling early after acute myocardial infarction. Circulation 2000; 101: 2734-2741

[67] Pontone G, Guaricci Al, Andreini D et al. Prognostic stratification of patients with ST-segment-elevation myocardial infarction (PROSPECT): A cardiac magnetic resonance study. Circ Cardiovasc Imaging 2017; 10: e006428

[68] Eitel I, de Waha S, Wohrle J et al. Comprehensive prognosis assessment by CMR imaging after ST-segment elevation myocardial infarction. J Am Coll Cardiol 2014; 64: 1217-1226

[69] Orn S, Manhenke C, Greve O] et al. Microvascular obstruction is a major determinant of infarct healing and subsequent left ventricular remodelling following primary percutaneous coronary intervention. Eur Heart ] 2009; 30: 1978-1985

[70] Roes SD, Kelle S, Kaandorp TA et al. Comparison of myocardial infarct size assessed with contrast-enhanced magnetic resonance imaging and left ventricular function and volumes to predict mortality in patients with healed myocardial infarction. Am J Cardiol 2007; 100: 930-936

[71] Kelle S, Roes SD, Klein C et al. Prognostic value of myocardial infarct size and contractile reserve using magnetic resonance imaging. J Am Coll Cardiol 2009; 54: 1770-1777

[72] Kuruvilla S, Adenaw N, Katwal AB et al. Late gadolinium enhancement on cardiac magnetic resonance predicts adverse cardiovascular outcomes in nonischemic cardiomyopathy: A systematic review and meta-analysis. Circ Cardiovasc Imaging 2014; 7: 250-258

[73] Abbasi SA, Ertel A, Shah RV et al. Impact of cardiovascular magnetic resonance on management and clinical decision-making in heart failure patients. J Cardiovasc Magn Reson 2013; 15: 89

[74] Gulati A, Jabbour A, Ismail TF et al. Association of fibrosis with mortality and sudden cardiac death in patients with nonischemic dilated cardiomyopathy. JAMA 2013; 309: 896-908

[75] Lehrke S, Lossnitzer D, Schob M et al. Use of cardiovascular magnetic resonance for risk stratification in chronic heart failure: Prognostic value of late gadolinium enhancement in patients with non-ischaemic dilated cardiomyopathy. Heart 2011; 97: 727-732

[76] Klem I, Weinsaft JW, Bahnson TD et al. Assessment of myocardial scarring improves risk stratification in patients evaluated for cardiac defibrillator implantation. J Am Coll Cardiol 2012; 60: 408-420

[77] Alba AC, Gaztanaga J, Foroutan F et al. Prognostic value of late gadolinium enhancement for the prediction of cardiovascular outcomes in dilated cardiomyopathy: An international, multi-institutional study of the minicor group. Circ Cardiovasc Imaging 2020; 13: e010105

[78] Iles L, Pfluger H, Lefkovits L et al. Myocardial fibrosis predicts appropriate device therapy in patients with implantable cardioverter-defibrillators for primary prevention of sudden cardiac death. J Am Coll Cardiol 2011; 57: $821-828$

[79] Grun S, Schumm J, Greulich S et al. Long-term follow-up of biopsy-proven viral myocarditis: Predictors of mortality and incomplete recovery. J Am Coll Cardiol 2012; 59: 1604-1615

[80] Grani C, Eichhorn C, Biere L et al. Prognostic value of cardiac magnetic resonance tissue characterization in risk stratifying patients with suspected myocarditis. J Am Coll Cardiol 2017; 70: 1964-1976

[81] Mewton N, Dernis A, Bresson D et al. Myocardial biomarkers and delayed enhanced cardiac magnetic resonance relationship in clinically suspected myocarditis and insight on clinical outcome. J Cardiovasc Med (Hagerstown) 2015; 16: 696-703

[82] Filippetti L, Mandry D, Venner C et al. Long-term outcome of patients with low/intermediate risk myocarditis is related to the presence of left ventricular remodeling in addition to the MRI pattern of delayed gadolinium enhancement. JACC Cardiovasc Imaging 2018; 11: 1367-1369 
[83] Bruder O, Wagner A, Jensen C] et al. Myocardial scar visualized by cardiovascular magnetic resonance imaging predicts major adverse events in patients with hypertrophic cardiomyopathy. J Am Coll Cardiol 2010; 56: 875-887

[84] Weng Z, Yao J, Chan RH et al. Prognostic value of LGE-CMR in HCM: A meta-analysis. JACC Cardiovasc Imaging 2016; 9: 1392-1402

[85] Chan RH, Maron B], Olivotto I et al. Prognostic value of quantitative contrast-enhanced cardiovascular magnetic resonance for the evaluation of sudden death risk in patients with hypertrophic cardiomyopathy. Circulation 2014; 130: 484-495

[86] Ruberg FL, Appelbaum E, Davidoff R et al. Diagnostic and prognostic utility of cardiovascular magnetic resonance imaging in light-chain cardiac amyloidosis. Am J Cardiol 2009; 103: 544-549

[87] Mekinian A, Lions C, Leleu X et al. Prognosis assessment of cardiac involvement in systemic al amyloidosis by magnetic resonance imaging. Am J Med 2010; 123: 864-868

[88] Austin BA, Tang WH, Rodriguez ER et al. Delayed hyper-enhancement magnetic resonance imaging provides incremental diagnostic and prognostic utility in suspected cardiac amyloidosis. JACC CardiovasC Imaging 2009; 2: 1369-1377

[89] Fontana M, Pica S, Reant P et al. Prognostic value of late gadolinium enhancement cardiovascular magnetic resonance in cardiac amyloidosis. Circulation 2015; 132: 1570-1579

[90] White JA, Kim HW, Shah D et al. CMR imaging with rapid visual T1 assessment predicts mortality in patients suspected of cardiac amyloidosis. JACC Cardiovasc Imaging 2014; 7: 143-156

[91] Benjamin EJ, Virani SS, Callaway CW et al. Heart disease and stroke statistics-2018 update: A report from the american heart association. Circulation 2018; 137: e67-e492

[92] Dweck MR, Joshi S, Murigu T et al. Midwall fibrosis is an independent predictor of mortality in patients with aortic stenosis. J Am Coll Cardiol 2011; 58: 1271-1279

[93] Quarto C, Dweck MR, Murigu T et al. Late gadolinium enhancement as a potential marker of increased perioperative risk in aortic valve replacement. Interact Cardiovasc Thorac Surg 2012; 15: 45-50

[94] Weidemann F, Herrmann S, Stork S et al. Impact of myocardial fibrosis in patients with symptomatic severe aortic stenosis. Circulation 2009; 120 : 577-584

[95] Dang Y, Hou Y. The prognostic value of late gadolinium enhancement in heart diseases: An umbrella review of meta-analyses of observational studies. Eur Radiol 2021; 31: 4528-4537

[96] Wesbey GE, Higgins CB, McNamara MT et al. Effect of gadolinium-DTPA on the magnetic relaxation times of normal and infarcted myocardium. Radiology 1984; 153: 165-169
[97] Nishimura T, Yamada Y, Hayashi M et al. Determination of infarct size of acute myocardial infarction in dogs by magnetic resonance imaging and gadolinium-DTPA: Comparison with indium-111 antimyosin imaging. Am J Physiol Imaging 1989; 4: 83-88

[98] Judd RM, Lugo-Olivieri CH, Arai M et al. Physiological basis of myocardial contrast enhancement in fast magnetic resonance images of 2-day-old reperfused canine infarcts. Circulation 1995; 92: 1902-1910

[99] Wu KC, Zerhouni EA, Judd RM et al. Prognostic significance of microvascular obstruction by magnetic resonance imaging in patients with acute myocardial infarction. Circulation 1998; 97: 765-772

[100] de Roos A, van Rossum AC, van der Wall E et al. Reperfused and nonreperfused myocardial infarction: Diagnostic potential of Gd-DTPA enhanced MR imaging. Radiology 1989; 172: 717-720

[101] McNamara MT, Tscholakoff D, Revel D et al. Differentiation of reversible and irreversible myocardial injury by MR imaging with and without gadolinium-DTPA. Radiology 1986; 158: 765-769

[102] Holtackers RJ, Wildberger JE, Wintersperger BJ et al. Impact of field strength in clinical cardiac magnetic resonance imaging. Invest Radiol 2021; 56: 764-772

[103] Moon JC, Messroghli DR, Kellman P et al. Myocardial T1 mapping and extracellular volume quantification: A society for cardiovascular magnetic resonance (SCMR) and CMR working group of the european society of cardiology consensus statement. J Cardiovasc Magn Reson 2013; 15: 92

[104] Ugander M, Bagi PS, Oki AJ et al. Myocardial edema as detected by pre-contrast T1 and T2 CMR delineates area at risk associated with acute myocardial infarction. JACC Cardiovasc Imaging 2012; 5: 596603

[105] Do DH, Eyvazian V, Bayoneta AJ et al. Cardiac magnetic resonance imaging using wideband sequences in patients with nonconditional cardiac implanted electronic devices. Heart Rhythm 2018; 15: 218-225

[106] Ranjan R, McGann C], Jeong EK et al. Wideband late gadolinium enhanced magnetic resonance imaging for imaging myocardial scar without image artefacts induced by implantable cardioverterdefibrillator: A feasibility study at 3 T. Europace 2015; 17: 483-488

[107] Bustin A, Fuin N, Botnar RM et al. From compressed-sensing to artificial intelligence-based cardiac MRI reconstruction. Front Cardiovasc Med 2020; 7: 17

[108] Holtackers RJ, Van De Heyning CM, Chiribiri AM et al. Dark-blood late gadolinium enhancement cardiovascular magnetic resonance for improved detection of subendocardial scar: a review of current techniques. J Cardiovasc Magn Reson 2021; 23: 96 